\title{
Planting the Seeds of Diversity
}

\author{
Elizabeth Holm
}

I have a passion for growing toma-

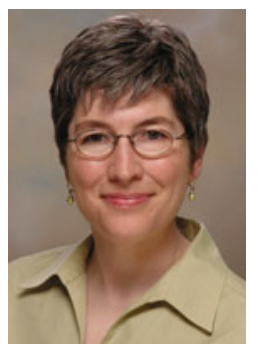

Elizabeth Holm

toes. In fact, I'm obsessed enough that my daughter once drew a picture showing me with my three kids: herself, my dog, and a tomato plant. Sadly, during last year's long, hot summer, my garden caught a virus, and most of my tomato plants shriveled. But not the Sweet 100's, or the Brandywines, or the Juliets. So I still enjoyed my summertime favorites.

Diversity is like that. Study after study shows that the diverse workplace is the most resilient, flexible, and productive. Experiences in different cultures can help team members overcome a challenging team dynamic; can enable an engineer to imagine a new and unique solution; or can open new product markets. Diversity-friendly practices (such as childcare leave) can even improve recruitment, retention, and productivity for everyone-not just underrepresented groups.

However, the diverse workplace doesn't happen by itself. Just as I choose a variety of tomato plants, employers must actively seek out a range of talents, experiences, and strengths. Diversity doesn't end with recruitment, either, any more than gardening ends with planting. The inclusive workplace must continue to nurture a sense of community that recognizes diverse contributions in order to retain the best and brightest.
This isn't an easy task, and the engineering professions have not excelled at it. During the time that medical school enrollment has soared from $7 \%$ to over $50 \%$ female, engineering has grown to - and stagnated at - only about $20 \%$ women. Unfortunately, the situation gets worse: After graduation,

\section{Study after study shows that the diverse workplace is the most resilient, flexible, and productive.}

women leave engineering jobs disproportionately compared to their male colleagues.

When my tomatoes began to turn brown, I sought out a Master Gardener. In engineering, our professional societies play that role, offering knowledge, experience, and resources that are not always accessible to individual members.

This issue of JOM collects some of that knowledge and experience in profiles of a few of our society's outstanding women leaders. With insights and ideas for succeeding in a predominately male profession, these women are role models for their fellow professionals, and their stories offer benchmarks for employers seeking to achieve an inclusive workplace.

Also highlighted this month is a new TMS endeavor: the first TMS summit to explore diversity and inclu- sion in the minerals, metals and materials sectors. While our focus on diversity may be new, TMS is actually doing what we do best: aggregating and disseminating resources to advance our members' careers and the profession as a whole. Moving beyond mere facts and figures, this summit will offer our professional members and their employers an opportunity to develop skills and tools to foster and to thrive in a diverse environment. The summit has already generated considerable excitement among our members and our sister societies. I hope you will join me in participating. Watch for details in future issues of JOM and on the TMS website.

Finally, this issue of $J O M$ presents the slate of 2014 TMS Board of Directors nominees - our future leadership. Over the years, TMS has benefited from volunteer leaders who are diverse in gender, age, technical background, sexual orientation, disability, race, and national origin. However, we cannot rest on past successes: Maintaining an inclusive community is an ongoing commitment. Please help TMS do just that, by encouraging members from all demographics to become involved in organizing symposia, participating in technical committees, and volunteering for leadership activities. Together we can plant the seeds of diversity that will grow into a robust, adaptable, dynamic, and strong professional community.

Elizabeth Holm is a professor with the Department of Materials Science \& Engineering, Carnegie Mellon University, Pittsburgh, PA; and the 2013 TMS President. 